This is an author produced version of a paper published in Journal of Social Philosophy.

This paper has been peer-reviewed but may not include the final publisher proof-corrections or pagination.

Citation for the published paper:

Erika von Essen \& Michael P. Allen. (2016) A Rabble in the Zoopolis? Considering Responsibilities for Wildlife Hybrids. Journal of Social Philosophy. Volume: 47, Number: 2, pp 171-187. http://dx.doi.org/10.1111/josp.12150.

Access to the published version may require journal subscription. Published with permission from: Wiley \& Sons Ltd.

Standard set statement from the publisher:

This is the peer reviewed version of the following article: Erika von Essen \& Michael P. Allen. (2016) A Rabble in the Zoopolis? Considering Responsibilities for Wildlife Hybrids. Journal of Social Philosophy. Volume: 47, Number: 2, pp 171-187, which has been published in final form at http://dx.doi.org/10.1111/josp.12150. This article may be used for non-commercial purposes in accordance with Wiley Terms and Conditions for Self-Archiving.

Epsilon Open Archive http://epsilon.slu.se 


\title{
A Rabble in the Zoopolis? Considering Responsibilities for Wildlife Hybrids
}

Authors:

\author{
Erica von Essen (corresponding author), Ph.D. researcher in Environmental \\ Communication, Swedish University of Agricultural Sciences \\ erica.von.essen@slu.se
}

\section{Michael P. Allen, Associate Professor in Legal, Political and Social Philosophy, East Tennessee State University}

allenmp@etsu.edu

In this article, we appeal to Hegel's concept of the rabble to examine the predicament of wildlife hybrids.

The EU Habitats Directive and the US Endangered Species Act presently exempt hybrids from legal protection and sanction their elimination as individuals, seeing them as threats to the genetic integrity of endangered species. In this paper, we first elucidate the legal, political and ethical problem of wildlife hybrids by first reviewing empirical research on the harms posed by admixed individuals within the Canis genus. We then point to a lacuna in Donaldson and Kymlicka's categorizations of non-human animals in Zoopolis, appealing to queer theory to show how canid hybrids are bereaved of rights and duties to welfare insofar as they defy assimilation into the existing political categories of domestic, liminal, and wild. The resulting predicament is that hybrids are adrift across political memberships in a zoopolis akin to Hegel's rabble - a population wronged by society that are a danger to themselves and others. Our responsibility for them is explicated with reference to the anthropogenic cause of their predicament and the limited prospects for finding them a settled estate. We conclude the paper by discussing a flexible partial public ownership scheme to meet our responsibilities for wildlife hybrids.

Keywords: Hybrids; Rabble; Zoopolis; Queer Theory; Animal Rights 


\section{Introduction}

In Zoopolis ${ }^{[1]}$, Donaldson and Kymlicka reconceive our duties to non-human animals in terms of political philosophy by drawing attention away from universal rights binding us to treat all animals (human and non-human) the same, on the basis of equal sentience ${ }^{[2]}$. Following Midgley ${ }^{[3]}$ and Palmer ${ }^{[4]}$, they appeal instead to a more relational conception of justice as entailing diverse special rights and duties. On this view, universal rights alone and corresponding duties of justice tell us remarkably little about the possibilities for differential but equal treatment for all members of zoopolis, or shared interspecies community. Indeed, Donaldson and Kymlicka appeal to three broad categories of animals as domestics, liminals, and wild respectively. What we owe to domestics, as our co-citizens, is relevantly different from what we owe to wild sovereigns, with whom we have more limited interactions. Likewise, duties owed to animals falling in these two categories is relevantly different from those duties owed to liminals, occupying an intermediate position between domestics and wilds.

In this paper, however, we examine cases of non-human animals who do not fall conveniently under any of these categories. In particular, we examine hybrid wildlife, canid admixtures, such as dogwolves and coy-wolves. For the most part, Donaldson and Kymlicka assume all animals have an easily recognizable 'home' or 'estate' in zoopolis, as domestic, liminal, or wild. To be sure, they are aware of cases in which individual animals or communities move along these categories in an inwards or outwards direction. ${ }^{[5]}$ For example, they address cases of humans selectively breeding animals into greater dependency and domestic co-citizenship. They also address cases of breeding for greater independence and sovereignty, as in the rewilding endangered species ${ }^{[1]}$. Here, they acknowledge that such inwards and outwards movements, establishing specific kinds of relationships with the animals, command responsibility-taking. But they entirely miss the phenomenon that concerns us: hybridizations in the wild resulting in directionless movements by new breeds that transgress the existing categories. These movements are directionless in the sense that the canid hybrids on which we focus are neither bred into co-citizenship or out into sovereignty, but can hardly be resolved as the middle category of denizen either. 
These hybrids are rather cast adrift by zoopolis that is responsible for their existence and outcast status. At present, conservation policy unsympathetic to hybrids ${ }^{[6]}$. Its withholding of protective duties to such animals fails to acknowledge the obligations generated by the various anthropogenic activities, including disruptive land-use, hunting and straying pets, that have resulted in their existence.

Indeed, as adrift between categories of political membership, they present a profound challenge to the legitimacy of zoopolis. This kind of challenge is in certain respects similar to that presented to early modern capitalist society by the emergence of a new class or rabble (pöbel): a class of poor and unemployed who defied categorization into any of the existing estates of civil society. Hegel saw the rabble as a population suffering an inherent injustice. Modern civil society had promised them equal rights as citizens of the state, but could not deliver on this promise given that the rabble lived outside the system of right governing the established estates, and the prospects for assimilation into these estates were slim to none. Hegel's attitude towards the problem of the rabble was deeply pessimistic, as “...one which agitates and torments modern societies." ${ }^{[7]}$ We believe that the problem of canid hybrids should likewise agitate and torment zoopolis. After all, hybrids occupy a position in zoopolis that resemble Hegel's rabble insofar as they do not fit into any of its existing estates and, for reasons we develop in the following sections, it is unclear to what extent they can be successfully directed into these estates. Moreover, canid hybrids, like Hegel's rabble, rightly command responsibility-taking by zoopolis.

Nonetheless, we are not as pessimistic about canid hybirds as Hegel was about the pöbel. While we do not see any singular solution to the problem of the hybrid rabble, we do believe that a variety of strategies are possible for zoopolis to take appropriate responsibility for the animals it has de facto generated. We argue that a strategy of 'sort and separate' - assimilation into existing estates - should be pursued when feasible. But there remain hybrid populations for whom assimilation is not feasible and, in these cases, more ad hoc responses to assuming responsibility for their welfare are necessary. Here, justifiable responses must pay close attention to those features of our relationships to canid admixtures that preclude the possibility of their absorption into the existing estates. We contend that if Hegel helps us 
to define the problem of anthropogenically-induced canid hybrids as a directionless population adrift in zoopolis that has failed to recognize their existence and status as rights-bearers, then the solution may be indicated by the political orientation of queer theory. That is, its orientation to a pluralism of relationships and statuses that deny assimilation into existing categories, but which nonetheless call for an appropriate recognition of their right ${ }^{[8]}$.

Obviously, there are limits to our heuristic appeals to Hegel and to queer theory. According to Hegel, the pöbel is defined psychologically by an attitude of resentment and indignation, conscious of civil society's broken promise ${ }^{[7]}$ Likewise, queer theory starts by acknowledging assertions by queer populations of their category-defying self-identifications. Category-defying canid admixtures cannot be defined analogously by their consciousness of having been done wrong by zoopolis or consciousness of their difference, no matter how maladapted. Indeed, our appeals to Hegel and queer theory are motivated only by our desire to highlight the inadequacy of existing zoopolitan categories, the limited possibilities for assimilation into these categories, and the imperative of flexible thinking about the open possibilities for establishing rights-recognizing relationship with hybrids in e.g. conservation policy.

In what follows, we explore these possibilities with respect to canid hybrids such as dog-wolves and coy-wolves. We first outline the anthropogenic causes and implications of such hybrids by reviewing the relevant empirical literature. Next, we identify the kinds of harms they suffer in virtue of their situation, emphasizing the unpredictability of their behaviors as directionless animals cast adrift by zoopolis. We then turn to the question of how zoopolis might appropriately take responsibility for those hybrids it has cast adrift, proposing a flexible partial ownership model for our duties towards them. From here, we discuss this model in light of the problem of public resentment towards canid hybrids. Finally, we briefly contrast our position with the stewardship model of responsibility-taking, responding to epistemic concerns about the unpredictability of hybrid behaviors and their future prospects.

\section{Anthropogenic cause of Canid Hybrids}


The Canis genus has a complex and contested evolutionary pedigree that continues to provoke controversy among taxonomists. This is especially so in North America, where five distinct taxa have been found to be isokaryotopic and interfertile. Here, hybridisation can occur between the gray wolf and the coyote ${ }^{[9]}$, the gray wolf and the eastern timber wolf ${ }^{[10]}$, the coyote and the eastern timber wolf ${ }^{[11]}$, the coyote and the red wolf ${ }^{[12]}$, and the coyote and the domestic dog ${ }^{[13]}$. In Europe, the gray wolf hybridizes mainly with the domestic dog ${ }^{[14]}$. However, sub-species of the gray wolf are sometimes identified for conservation purposes in the form of the Italian wolf, the Scandinavian wolf, the Iranian wolf and even subspecies of the latter and these, too, have been known to cross-breed with the domestic dog ${ }^{[15]}$.

To say that hybridisations between these Canis congeners along these lines is prevalent may be an overstatement. Research indicates that cross-breeding across species boundaries may have been an important part of the evolutionary legacy of the coyote ${ }^{[16]}$, the red wolf ${ }^{[17]}$ and domestic shepherd dogs in Europe ${ }^{[18]}$, even accounting for their vigor and increased adaptability in the form of 'hetereosis'. ${ }^{[19]}$ But scholars also suggest hybridization may in actual fact be a rare occurrence in the wild and that the presence of introgressed genes can often be attributed to the reproductive success of select individual hybrids some generations back. ${ }^{[20]}$ To this end, historical, episodic hybridization is usually demarcated from contemporary anthropogenic hybridization ${ }^{[18 \mathrm{a}, 21]}$.

In practice, the boundaries are blurred between natural and anthropogenic hybridization on the one hand, and between historical and contemporary hybridization on the other ${ }^{[6]}$. What can be stated is that the former is typically ascribed positive attributes in terms of resulting in novel gene recombinations and contributing to genetic diversity in inbred species ${ }^{[18 a, 22]}$. Contemporary hybridisations between canids, by contrast, is largely explained as due to anthropogenic breakdown of reproductive barriers between two previously reproductively isolated, allopatric canids. It is thus widely perceived as a threat to the genetic integrity of rare or endangered Canis taxa. On this view, hybridization across Canis is presented as a major conservation problem for practitioners today ${ }^{[15,23]}$. 
As far as Canis is concerned, we acknowledge the potential value of past cross-breeding in having promoted the viability and even the unique ecology of the species in existence today ${ }^{[24]}$. However, we also observe that contemporary hybridization poses some serious issues insofar as it is overwhelmingly anthropogenic. Indeed, hybridization in the wild is typically counteracted between sympatric canids by disparities in ethology, habitat, physiology and predation patterns that act as natural barriers to cross-breeding, thus potentially suggesting hybridization is the result of some unnatural disturbance $^{[15,25]}$. For one, the highly aggressive and territorial behavior of canids make cross-species interactions precarious and unlikely to result in mating ${ }^{[20 a, 26]}$. Because of anthropogenic impacts, however, changing endogenous and exogenous conditions now permit a higher degree of hybridization. The perhaps most significant factor influencing hybridization is habitat encroachment, including ecological homogenization and other spatial patterns of land-use ${ }^{[27]}$. Landscapes altered by climate change is often counted as another anthropogenic driver to hybridization ${ }^{[10,28]}$. Through the breaking down of reproductive barriers for either of the two species, congeners may find themselves cross-breeding in ranges where they are sympatric, either producing a stable hybrid zone or a 'hybrid swarm', typically at the expense of the rarer taxon - which for canids is typically some subspecies of the wolf ${ }^{[13,29]}$.

Anthropogenically mediated hybridization also occurs in more or less direct ways today through carelessness or artificial selection ${ }^{[18 \mathrm{a}, 20 \mathrm{~b}]}$. High numbers of free-ranging domestic dogs may constitute a primary mechanism for cross-breeding, particularly in parts of southern Europe. In the Carpathians, shepherd dogs are both intentionally ("to improve the breed") and unintentionally mated with wolves in the mountains ${ }^{[18 b]}$. In Iran, Khosravi, et al. ${ }^{[15]}$ found native farmers are either unaware of the consequences of keeping free-ranging dogs in wolf-dense areas, or actively breed wolf-dog hybrids at home by capturing wolves. Feral and stray dogs are a problem elsewhere ${ }^{[6]}$, but any free-ranging dogs in hybrid zones - hunting or lacking the supervision of their owner - have been found to be potential causes of hybridization. In the vast majority of cases of canid hybridisation, the cross-breeding is unidirectional between that of a male dog and a female wolf ${ }^{[18 b, 23,30]}$. In terms of plainly anthropogenic mediated 
hybridization, research also suggests private individuals, zoos and even non-governmental organisations may have (sometimes clandestinely) bred hybrid pups that have escaped or been purposely released to promote the viability of wild populations of wolves ${ }^{[31]}$. However, there may be reason to approach this as an unsubstantiated rumor perpetuated by hunters seeking to delegitimize wolf conservation programs ${ }^{[32]}$.

Once two interfertile congeners are sympatric, human activity can exacerbate chances of hybridization. For example, the research is clear on the link between hunting and increased hybridization $[21,25,33]$. Hunting pressure can also have serious implications on the social dynamics, pack behavior and breeding pairs of canids insofar as conventional patterns of organization become disrupted ${ }^{[10,23,34]}$. Hence, indiscriminate killing induces changes in intraspecific competition, and epistatic equilibria facilitate hybridization ${ }^{[18 a]}$. Mate choice is particularly vulnerable to human disruption of social systems by hunting in breeding times ${ }^{[35]}$. The elimination of conspecifics, especially that of genetically valuable breeders in the pack, may force reproductively active canids to choose hetereospecific mates nearby. In cases where the canid has been plainly anthropogenically transplanted to a new habitat in which its natural conspecifics are scarce, such as coyotes captured in Texas and released for sport hunting in the Southeast ${ }^{[30]}$, the reproductively active canid can seek out local dogs for mating. There is reason to believe the impact of hunting on hybridization may be even more intricate than the above mechanisms suggest. Indeed, harvesting pressure has been found to negatively influence the size of wolves, which may make them fundamentally more prone to cross-breed with the smaller coyotes in the area ${ }^{[36]}$.

\section{Hybrids as Harm to Themselves and Others}

It is admittedly difficult today to find wildlife that has not been anthropogenically mediated in some way. But the predicament of hybrids poses a unique challenge to conservation practitioners given their allegedly threatening properties toward themselves, to the ecosystem, and to humans. Indeed, policy and law have not taken well to the actual or perceived risk of hybrids in the wild ${ }^{[37]}$. The US Endangered Species Act, the Bern Convention and the EU Habitats Directive exempt hybrids from the protection duties accorded to their endangered congeners and, in some cases, encourage active removal of hybrids 
from the wild ${ }^{[6,14 b, 38]}$. In the US, for example, the Red Wolf Management Adaptive Plan (RWAMP) euthanized hybrids and sterilized coyotes to preclude further hybridization with the rare red wolves in the late $1990 \mathrm{~s}^{[39]}$. In Europe, the genetic threat posed by domestic dogs to the (often painstakingly and unpopularly) reintroduced and protected gray wolf has resulted in de facto sanctioning of the elimination of hybrids to safeguard the status of wolves in the Habitats Directive ${ }^{[40]}$, though somewhat undesirably by hunters who may now be able to kill wolves under the legal loophole "I thought I was shooting a hybrid!" (Trouwborst, 2014a). Given the aversion to hybrids both among the public and policy-makers, we now identify the ways in which canid hybrids have been understood as particularly problematic.

First, there are concerns about the unpredictability of hybrids and their potential impacts on human interests. That wolves today have "lost their wildness" as a combined result of hybridisation and loss of lethal control is a common charge levelled by hunters toward the recovering, now protected European wolf population ${ }^{[32]}$. While partly another discursive strategy to delegitimize their conservation, research affirms this possibility. Wolf-dog hybrids may lose wildness, their fear of humans, and specialize in predating on livestock or domestic animals in human settlements ${ }^{[30,40]}$. Where coyote genes are admixed, hybridisation may further embolden canids to adapt to suburban landscapes, at least those with favourable habitat characteristics ${ }^{[41]}$. Indeed, research demonstrates hybridisation can have profound effect on gene expressions in emotion and ethology regulated centers of the brain, impacting tameness and wildness ${ }^{[42]}$. If co-existence with the wolf is sought, then, hybridisation poses a clear challenge.

Second, in terms of impact on their own well-being, hybrids can be either well-adapted or maladapted depending on circumstances. Overwhelmingly, however, conservation policy draws attention to the negative consequences of new genetic recombinations in the present. Hybridisation can potentially depress the fitness of admixed canids by disrupting the timing of reproductive cycles, undermining immunological resistance to diseases and impairing physiological and ethological processes ${ }^{[21]}$. The disruption of locally adapted gene complexes to environments has also been cited as a threat with hybrids in general ${ }^{[43]}$. In crosses between a male dog and a female wolf, the dominant gene flow in canid 
hybridisations ${ }^{[18 b]}$, chances of survival also tend to be low for the hybrid pubs given lack of parental care from male dogs that would otherwise be accorded to full wolf pups. ${ }^{[15,20 a]}$.

Third, the 'swamping' of rare genes by more prevalent ones through hybridisation poses a threat to the genetic integrity of endangered taxa ${ }^{[44]}$. This entails a “...loss of unique genetic, morphological, behavioral, or ecological characteristics that have evolved in local populations over time" ${ }^{[43]}$ (p. 485 ). Indigenous biota is held as particularly vulnerable to the invasive introgression posed by 'new' species

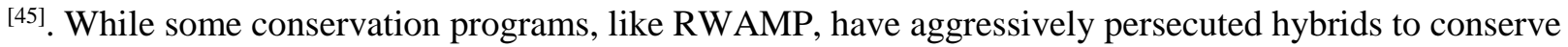
the species purity of endangered taxa, some legislation is now beginning to recognize the injustice this poses to anthropogenically generated hybrids. Indeed, the Netherlands, Germany and Estonia now extend passive protection duties to hybrids of species listed as endangered under the Bern Convention. The problem with this scheme, however, is that passive protection (i.e. desisting to kill) means simply leaving the hybrids in the wild. There is reason to be critical toward this hands-off approach's solution to moral problems as withdrawing, when we observe that leaving hybrids in the wild means leaving them in an undesirable predicament. As contended above, they may be maladapted within zoopolis both in terms of intraspecies dynamics and, politically, in terms of the danger they pose to humans. For one, these admixed individuals may be more prone to mate with other hybrids ${ }^{[23]}$, leading to a positive feedback of hybridization. Research also indicates hybrid coyotes are ill-equipped to take over the role of apex predator in many ecosystems where this position was previously held by the larger wolf, and that this may have detrimental consequences on trophic interactions and in particular the local ungulate fauna ${ }^{[10]}$.

We have emphasised three primary ways in which hybrids are adrift in zoopolis, insofar as they are permitted habitation at all: as danger to humans, as danger to themselves, and as danger to the ecosystem. This predicament is exacerbated by an inability to resolve hybrids in terms of existing political categories along those envisioned by Donaldson and Kymlicka. When wolves, dogs and coyotes crossbreed, it is rare that the offspring can be clearly resolved as sovereign, co-citizen or denizen. Similarly, when a sovereign wolf mates with a domestic dog, the result is not a hybrid denizen, but arguably an 
emergent category. While backcrossed hybrids integrated in their mother's pack may at times be relatively well-adapted to sovereignty, Sears, et al. ${ }^{[11]}$ demonstrate landscape, land-use and human activity ultimately determine which parental traits will be expressed. Emergence may therefore be said to result from the co-mingling of evolutionary lineages in novel ways that pertain both to genetics and place. This means that many factors complicate the morphology and behaviour of hybrids and result in unpredictability in terms of their re-integration. Hence, while not all negative consequences outlined above may appear, the risk alone has been sufficient for policy-makers to deny hybrids an estate in existing categories in zoopolis.

\section{Responsibility-Taking and the Partial Ownership Model.}

Based on the preceding review of empirical research on canid hybrids, we contend that they are properly characterized as a rabble to the extent they have no estate of their own. As resulting from anthropogenic causes, we claim that (1) we are overwhelmingly responsible for creating the canid hybrid rabble and (2) we bear responsibility for the consequent harms they pose to themselves and others. Moreover, we contend that there is little prospect for fully assimilating them into any of the established estates of zoopolis, as domestic co-citizen, liminal, and wild respectively. Characterising hybrids as 'failed states' of sovereigns ${ }^{[1]}$, to be brought back up to sovereignty, is thus arguably a mischaracterization of an emergent category not neatly resolvable as either of its parent categories. Consequently, we believe canid hybrids pose a problem similar to that engaged by queer theory of giving appropriate forms of recognition for those who defy assimilation into the existing categories of rights-holders. Indeed, insofar as conservation policy mentions hybrids at all, the EU Habitats Directive and the US Endangered Species Act take the view that these are disposable animals to whom we owe nothing in terms of special rights of recognition for their difference. We assert, however, that such a lack of recognition of their difference by a zoopolis is unconscionable, given our responsibility for their existence as animals whose unpredictable behaviors necessarily pose risks of harms to themselves and others. 
Indeed, the only things that these hybrids have in common is that they are all canids, and they are out of place. Between them, though, there are so many relevant differences depending on specific admixtures that there is no feasible blanket solution to hybrid maladaptation. This might suggest that the most we can do is to separate various hybrids as best we can into the existing estates of zoopolis. To be sure, this may be possible in a limited number of cases. For instance, hybrids who are less than ten percent wolf could be brought fully into domestic co-citizenship and perhaps even trained for public sector jobs as, say, search and rescue dogs or police K9s. But domestication or public work is uncertain and potentially a threat to public safety for canid hybrids with higher genetic admixture from wolves. What of sorting them into existing denizen and sovereign, as opposed to citizen, categories? Here, a sorting and separation strategy would likely amount to little more than public commitment to actively withdrawing from food conditioning so as to minimize their habituation to humans. This might entail making a concerted effort to eliminate opportunities for hybrids to scavenge from garbage, target pets, consume food-stuffs intentionally left out for other animals, or carrion inadequately disposed by hunters in semi-forested areas, measures now suggested by the literature ${ }^{[46]}$. But it is hard to avoid the conclusion that any such 'hands off' approach - pushing animals we have created into a wild category to which we know they are, in varying degrees, maladapted - is merely an abnegation of our responsibility for their welfare. As contended, to do so is to conceive of hybrids as failed or compromised version of their parents, to be regressed into either of these states, and not as an emergent category with rights of its own.

As an alternative to sorting and separating, then, we propose adopting a model of partial ownership of canid hybrids analogous to the partial ownership of semi-feral animals, such as horses. Semi-feral horses and horse breeds are neither domesticated nor trained to perform any jobs in zoopolis, such as providing mounts for riders or carrying burdens. Nonetheless, they are privately owned by individuals or associations. For the most part, their owners leave these animals in a natural condition to run in the wild. But they also take responsibility for their welfare, periodically rounding them up in order to wean foals and administer routine or emergency veterinary care. This model of partial private 
ownership and responsibility-taking provides a useful guide for more flexibly understanding our duties to canid hybrids for whom assimilation into sovereignty or co-citizenship is unfeasible. After all, such hybrids are animals that we have created but which we can neither successfully domesticate nor train, except in a sorely limited range of cases. But we cannot simply abandon them and take an exclusively hands-off approach, as if there were nothing more we could do to promote their safety and well-being.

As a society, we could and indeed should take responsibility for canid hybrids by assuming flexible commitments to partial public ownership, according to which we monitor them and provide veterinary or other kinds of animal-welfare interventions. This may, for example, include habitat maintenance insofar as we ensure (1) the availability of a diversity of wild prey to prevent hybrids from straying into human settlements and predating on domestic animals and (2) keep human encroachment in this habitat at a suitable level in terms of road density, hunting and agricultural activity. Further, we stress that the partial ownership of hybrids should be assumed a societal or public responsibility and not just a private ownership responsibility of individuals or associations. This is partly to reflect the challenge that a fugitive resource like wildlife poses to local property rights, calling for larger management areas geographically and politically ${ }^{[47]}$. But privatization of wildlife must also be heeded as such a neoliberal approach to conservation can weaken the public's sense of responsibility for wildlife as a common resource, and lead to the commodification of the animals ${ }^{[48]}$. To conceive of hybrids in terms of property in any traditional landed property theory, therefore, is potentially harmful, even if canid hybrids are unlikely to be commodified as game resources given their protected status.

But between hybrids constituting sovereign ferae naturae to be cared for by no one and constituting traditional 'property', the partial public ownership scheme is most appropriate. We note here that in the common tradition, wildlife is typically ownerless until it is wounded by e.g. a hunter (proprietor). At this point, the latter assumes a responsibility for the animal not unlike the responsibility entailed by a property owner relationship. The insistence that animals that have somehow been mediated by anthropogenic activity should remain ferae naturae demonstrably absolves moral and legal 
responsibility in conservation ${ }^{[49]}$. Indeed, we have argued in particular that these hybrids are generated directly or indirectly by anthropogenic activity, which implies a weakened ownership with responsibility entailed in our relationship. This reasoning means we similarly consider abandoned or stay domestics to be a public responsibility, rather than a private one. Not only is it unrealistic to suppose that the problem of strays can be addressed solely by concerned individuals assuming responsibility for them. But it is also rightly the collective responsibility of the society that created these animals as a category to see to their welfare in the future. That said, however, public responsibility-taking proves to be significantly different in the case of abandoned or stray domestics as opposed to the rabble of canid hybrids. Ideally, such responsibility-taking for strays aims at the goal of reintegration. This is evident from our longstanding public commitments to sheltering them and encouraging adoptions, as well as providing general assistance should we prove unable to find them any more settled home in zoopolis. By contrast, however, full assimilation into existing estates is inappropriate for the rabble of canid hybrids for the reasons we have already given.

Nonetheless, rejecting full assimilation does nothing to diminish the normative significance of the commitment to providing general assistance to the hybrids as semi-feral animals for whom we collectively assume partial ownership responsibilities as a society. This may be appreciated best by considering the contrast with our duties to sovereigns whose existence in the wild is something for which we bear no responsibility in the manner of domestics and strays. Sometimes, it will be argued that we are not only responsible for a rabbit we have domesticated should it suffer injury in our home or garden ${ }^{[50]}$. But we are also responsible should we find it injured in the woods, supposing it has strayed. That is, we are responsible for rendering general assistance given we are responsible for having created its dependency on us and its relative vulnerability in the wild. In contrast, we have no such responsibility for a wild rabbit similarly injured in the woods. We are not responsible because we did not create its vulnerability in the wild or induce a dependency. Moreover, on this view, we should forego general assistance "because of epistemic uncertainty regarding maximization of welfare" [50]. 
Regardless of what we make of this contention regarding the propriety of not assisting the wild rabbit, we can say this much concerning the rabble of semi-feral canid hybrids. We are responsible for their vulnerability in the wild in much the same way that we are responsible for distressed domestics in the wild. Moreover, the issue regarding epistemic uncertainty as regard general duties of welfare is quite different for canid hybrids. As stressed in the previous section, we are uncertain about the ability of such a diverse hybrid population to successfully adapt to a sovereign estate. Uncertainly in this sense trumps any concern about our meddling in such an estate. It is trumped because canid hybrids have no estate in the wild. Consequently, aside from our role in having created them as vulnerable animals without a home in a zoopolis, it is epistemic uncertainty about their ability to prosper in the wild - absent monitoring and periodic general assistance - that underwrites duties to rabble of hybrids, as distinct from wild sovereigns.

\section{Public Resentment of Canid Hybrids}

Nonetheless, it may still be insisted that our goal should one of assimilation in a more fundamental sense than sorting and separating into one of the established estates of zoopolis. Even if assimilation into one of these estates is rejected, our goal should still be to integrate the canid hybrid rabble into zoopolis by recognizing them as having legal standing and rights, if not a settled estate. But on what level of public authority might this responsibility to the canid rabble be met? We believe that it should be met on multiple levels to best address the challenge ${ }^{[47]}$. On the supranational level, the EU Habitats Directive should be amended to explicitly recognize the rights and standing of hybrids. On the national level, recognition should likewise be codified in Environmental Protection Agencies in European member states and the US Fish and Wildlife Service. Indeed, recognition and codification at these levels is a necessary step towards establishing a just political relation, given that hybrids presently have little or no standing under existing law. Nonetheless, we consider it advisable that supra- and national legal directives are also rooted in local decision-making processes. 
To this extent, we advocate that decisions about how best to realize their rights and meet our obligations to hybrids should be delegated to more local authorities. We advocate this for two reasons. On the one hand, recognition of the rights of hybrids and our specific duties towards them is likely to encounter what we previously called 'hybrid prejudice,' especially from hunters who are, in many cases, already resentful of the protections afforded to wild sovereign wolves ${ }^{[51]}$. Consequently, any legallymandated duties to canid hybrids are likely to encounter similar resentment about yet another protection directive "from above", perhaps resulting in non-compliance ${ }^{[52]}$ and the undermining of hunters' conception of these animals as public wildlife, seeing them instead as the pets of government agencies. The issue of legitimacy for such conservation directives among hunters is a complex one, which we have addressed elsewhere ${ }^{[53]}$, indeed contending that the closer decision-making on wolves is to the affected citizens, in particular, the likelier they are to be legitimate. This is provided there are international standards in place to check the responsibility of regional bodies and to address the large ranges and mobility of canids across jurisdictions ${ }^{[47,54]}$. More than that, however, the delegation of decisions concerning the planning and implementation of particular assistance to hybrids is appropriate from the perspective of efficiency and effectiveness. After all, regional decisions regarding the delivery of assistance are likely to be more sensitive to the particular hybrids in an area. Owing to the diversity of admixtures and behaviors with topography, prey availability and individual morphology ${ }^{[11,41,55]}$, local packs and adaptations will require particular actions that may not be generalizable to other areas.

But still the public resentment associated with hybrids might take a different and possibly more pernicious turn. Here, we have in mind not resentment towards directives from above, but instead the hybrids themselves. We found the public is already skeptical toward hybrids because they defy categorization $^{[33]}$. But they may also come to be seen as permanent 'wards of the state' with our welfare scheme. That is, permanent dependents on welfare that can neither be integrated into our homes nor assigned useful work, nor function independently of us as sovereigns. As we have noted several times, hybrids are already the focus of prejudice. Institutionalizing their rights and status under law as welfare 
dependents who give nothing back to zoopolis in terms of becoming lovable pets or helpful service animals is only likely to make matters worse. We might subject hybrids to the kind of resentment that is often directed toward the long-term unemployed and unemployable as 'scroungers' choosing to live at the expense of taxpayers. What, though, might be said about such resentment when it is directed towards the rabble of canid hybrids as opposed to the unemployed human recipients of assistance from the state? Resentment towards to latter is often based on an assumption that dependence on the state has been chosen: viz the long-term unemployed have simply chosen not to continue looking for work, and so on. This assumption may well be mistaken and indeed it must be seen as mistaken on Hegel's analysis of the rabble of paupers who cannot all be integrated into the modern market economy.

We see no reason, however, to engage in controversy over whether the long-term unemployed are genuinely excluded from being of civil society by the market economy or whether they are choosing to live at the expense of taxpayers. Instead, we content ourselves with pointing out that the assumption underlying this controversy has no application to the rabble of canid hybrids. That is, these animals cannot plausibly be said to have made any kind of conscious choice that would make them fitting targets of our resentment and moral opprobrium. The only morally relevant choices in this context of discussion are those we have quite consciously made to protect ourselves by excluding them from our homes and urban spaces. We have elected to exclude them for our own protection, knowing that they are unlikely to prosper in the wild without our continued monitoring and periodic assistance. Any resentment towards hybrids as welfare dependents is therefore utterly misplaced. Indeed, the onus of moral justification and responsibility lies squarely with us, and not them. But still it might be contended that we are morally at fault for having consciously created their dependency on us through our ongoing interventions - a dependency that we have not just created, but also entrenched at multiple levels of legal authority from the supranational to the local. 


\section{Rejecting the Stewardship Model of Responsibility-Taking}

Finally, this latest argument could begin by conceding our point from the last section that hybrids have no estate in the wild and, as such, we cannot meddle in an estate that does not exist. It could also concede our claim that epistemic uncertainty about their ability to prosper in the wild trumps epistemic uncertainty about meddling in the estate of some actual wild sovereign. But it could then go on to advance a different kind of claim about epistemic uncertainty. That is, uncertainty about whether the welfare policies we adopt now might make it less likely that a wild sovereign estate for canid hybrids should emerge in the long run for future generations of hybrids. Indeed, as we discussed in the second section of this article, available empirical data demonstrates the perceived unpredictability and maladaptation of hybrid behaviors in the present. But how can we know that welfare provisions for the vulnerable present generation of hybrids are not impeding a long run evolutionary process of adaptation to the wild, thereby sacrificing future generations for the present? The underlying assumption of the partial ownership model of taking responsibility for hybrids we have proposed is that they cannot in due course of time graduate to sovereignty and full ownership of themselves, asserting their independence of us.

But that, in turn, could be a false assumption. How can we know? Normatively speaking, a condition of independence is surely preferable to one of ongoing dependence ${ }^{[1]}$. Consequently, we should desist from policies that could obstruct the more desirable outcome: hybrid sovereignty and independence in the long run. On this view, the 'relatively interventionist' stewardship model ${ }^{[1]}$ in which we unilaterally manage all hybrids must be rejected on two accounts: first, because it could potentially deprive some hybrids of future sovereignty; second, because it may induce the dependency of already meaningfully sovereign hybrids. Furthermore, because of hybrid diversity and the impossibility of a blanket solution or reserve to deal with hybrids, Donaldson and Kymlicka's stewardship model is unadvisable. If we knowingly maintain animals (whether human or non-human) in a condition of dependency when we are also aware that doing so could prevent their graduation to independence, then we are behaving unjustly. In other words, flexible recognition of their difference requires that we should 
always hold open the prospect of future independence. This may be supported by the observation that canid packs frequently demonstrate autonomy through having an internal authority regime ${ }^{[56]}$. If this argument is correct, then it would if not categorically rule out the stewardship model, present a case against it.

But, that said, we do not believe that the argument carries much weight and that stewardship for hybrids may be exercised in the partial public ownership scheme proposed above, provided a responsive ad-hoc approach undergirds it. There are, after all, examples both from human and animal welfare where stewardship has gradually flourished into new sovereign relations. This may be seen in the case of transitional political authorities facilitating the movement of failed or post-conflict states to sovereign independence, or conservationists caring for orphaned infant animals before reintroducing them to the wild. So, the idea that care, even over a long period of time, translates into eternal dependency, does not wholly obtain. There is ultimately epistemic uncertainty about what the future might hold for the diversity of canid hybrids. It may be that further hybridization and adaptation processes lead to more sovereigns or more domestics or liminals, or more semi-feral dependents. This ultimately remains unknowable: only time can tell.

Consequently, we again assign lexical priority to epistemic uncertainty about the predictability of hybrid behaviors - including the behaviors of future generations, given the wide diversity of genetic admixtures. If we hold open the future possibility of graduating to independence by desisting from monitoring and assistance, then we may well be foreclose the future prospect of hybrid graduating to domestication or liminality. Moreover, we foreclose any prospect of justice for semi-feral hybrids who remain semi-feral into the indefinite future. Here, we stress that it as an empirical question which policies and interventions succeed in establishing a suitably flexible and just relation. The effectiveness of any policies we undertake should therefore be subject to constant review in light of the emergence of new facts about how our interventions are affecting particular populations. But it is rank irresponsibility based on an absurd and impossible quest for certainty - to claim that we should simply desist from any 
welfare interventions or assistance due to our uncertainly about any number of possible future outcomes. Indeed, given the gravity of our moral responsibility for the situation of diverse canid hybrid populations, justice for hybrids commits us to context-sensitive and revisable intervention policies.

\section{Conclusion}

In this article, we have pushed the discussion of hybrids in the empirical literature beyond its present apolitical focus. We did this by addressing a certain lacunae in Donaldson and Kymlicka's Zoopolis. This concerns the exclusion of hybrids from the established estates of domestic, liminal, and wild. In this respect, we have argued that canid hybrids may be understood by analogy with the rabble (pöbel) in Hegel, in these sense they have no established estate in zoopolis. Not only are we responsible for their exclusion as a rabble without an estate, but we are also responsible for their welfare. We are responsible insofar as we are the anthropogenic cause of their situation as directionless and adrift, posing risks of harms to themselves and others. Above all, we have argued that canid hybrids are owed legal recognition, status and rights in zoopolis, none of which are presently granted to them in supranational and national law. That is, they are owed recognition for their specific differences as animals with limited prospects for assimilation into the existing estates. In order to elucidate the need for recognition of non-assimilable differences, we have appealed to an analogy to the political dimension of queer theory and its commitment to recognizing the rights of those who do not fit into existing categories of rights-holders.

Granting hybrids recognition and standing under law at multiple levels is a first step towards establishing a just and appropriate political relation. It is only a first step, however, because the variability of genetic admixtures and the unpredictability of their behaviors require us to hold open a range of different future prospects for prospering with or without our assistance. To this extent, we rejected a stewardship model of responsibility-taking as contributing to ongoing dependency for those hybrids 
potentially capable of meaningful autonomy in the future. Instead, we favored a flexible and ad-hoc approach to taking responsibility for their welfare based on the model of partial public ownership, warranting interventions for those hybrids that defy assimilation and remain semi-feral. This is normatively appropriate given our responsibility for their situation as directionless animals and their attendant vulnerabilities. Finally, given or responsibilities for these animals, we affirm that there is no justifiable basis for resentment against them, even if they remain dependents for whom we have assumed and must indefinitely sustain partial ownership responsibilities.

\section{Acknowledgements:}

We would like to thank Dr. Torbjörn Ebenhard with the Swedish Biodiversity Centre at the Swedish University of Agricultural Sciences for sharing his expertise with us regarding wolf hybrids. We are also grateful to the two particularly good anonymous reviewers.

\section{Notes}

[1] S. Donaldson, W. Kymlicka, Zoopolis Oxford University Press, Oxford, (2011).

[2] P. Singer, Animal Liberation, HarperCollins, (1975).

[3] M. Midgley, Animals and Why They Matter, University of Georgia Press, Athens, (1983).

[4] C. Palmer, Animal Ethics in Context, Columbia University Press, New York, (2010).

[5] S. Donaldson, W. Kymlicka, A Defense of animal citizens and sovereigns. Law, Ethics and Philosophy (2013), (1), 143-160.

[6] A. Trouwborst, Exploring the Legal Status of Wolf-Dog Hybrids and Other Dubious Animals: International and EU Law and the Wildlife Conservation Problem of Hybridization with Domestic and Alien Species. Review of European, Comparative \& International Environmental Law (2014), no. 23 (1), 111-124.

[7] G. W. F. Hegel, Elements of the Philosophy of Right, Cambridge University Press, (1998). (p.267)

[8] J. Butler, in The Lesbian and Gay Studies Reader (Eds.: H. Abelove, M. Aina Barale, D. Halperin), Routledge, New York, (1990), pp. 307-320.

[9] L. D. Mech, B. W. Christensen, C. S. Asa, M. Callahan, J. K. Young, Production of Hybrids between Western Gray Wolves and Western Coyotes. PLOS ONE (2014), no. 9 (2), e88861.

[10] L. Y. Rutledge, B. N. White, J. R. Row, B. R. Patterson, Intense harvesting of eastern wolves facilitated hybridization with coyotes. Ecology and Evolution (2012), no. 2 (1), 19-33.

[11] H. Sears, J. Theberge, M. Theberge, G. Thornton, D. Campbell, Landscape Influence on Canis Morphological and Ecological Variation in a Coyote-Wolf C. lupus $\times$ latrans Hybrid Zone, Southeastern Ontario. The Canadian Field-Naturalist (2003), no. 117 (4), 589-600.

[12] R. M. Nowak, N. E. Federoff, Validity of the Red Wolf: Response to Roy et al. Conservation Biology (1998), no. 12 (3), 722-725. 
[13] J. H. Bohling, L. P. Waits, Assessing the prevalence of hybridization between sympatric Canis species surrounding the red wolf (Canis rufus) recovery area in North Carolina. Molecular ecology (2011), no. 20 (10), 2142-2156.

[14] aC. F. Klutsch, E. H. Seppala, T. Fall, M. Uhlen, A. Hedhammar, H. Lohi, P. Savolainen, Regional occurrence, high frequency but low diversity of mitochondrial DNA haplogroup d1 suggests a recent dog-wolf hybridization in Scandinavia. Animal genetics (2011), no. 42 (1), 100-103; bA. Trouwborst, September 12014 ed., Bern Convention on the Conservation of European Wildlife and Natural Habitats, (2014).

[15] R. Khosravi, H. R. Rezaei, M. Kaboli, Detecting hybridization between Iranian wild wolf (Canis lupus pallipes) and free-ranging domestic dog (Canis familiaris) by analysis of microsatellite markers. Zoological science (2013), no. 30 (1), 27-34.

[16] J. F. Benson, B. R. Patterson, Moose (Alces alces) predation by eastern coyotes (Canis latrans) and eastern coyote $\times$ eastern wolf (Canis latrans $\times$ Canis lycaon) hybrids. Canadian Journal of Zoology (2013), no. 91 (11), 837-841.

[17] M. K. Phillips, V. G. Henry, Comments On Red Wolf Taxonomy. Conservation Biology (1992), no. 6 (4), 596-599.

[18] aE. Randi, P. Hulva, E. Fabbri, M. Galaverni, A. Galov, J. Kusak, D. Bigi, B. Č. Bolfíková, M. Smetanová, R. Caniglia, Multilocus Detection of Wolf $<$ italic $>x</$ italic $>$ Dog Hybridization in Italy, and Guidelines for Marker Selection. PLoS ONE (2014), no. 9 (1), e86409; bN. Kopaliani, M. Shakarashvili, Z. Gurielidze, T. Qurkhuli, D. Tarkhnishvili, Gene Flow between Wolf and Shepherd Dog Populations in Georgia (Caucasus). Journal of Heredity (2014), no. 105 (3), 345-353.

[19] K. Hill, The Endangered Species Act: What Do We Mean by Species? Boston College Environmental Affairs Law Review (1993), no. 239

[20] aT. J. Wheeldon, L. Y. Rutledge, B. R. Patterson, B. N. White, P. J. Wilson, Y-chromosome evidence supports asymmetric dog introgression into eastern coyotes. Ecology and Evolution (2013), no. 3 (9), 3005-3020; bJ. García-Moreno, M. D. Matocq, M. S. Roy, E. Geffen, R. K. Wayne, Relationships and Genetic Purity of the Endangered Mexican Wolf Based on Analysis of Microsatellite Loci

Relaciones y Pureza Genética del Lobo Mexicano Basadas en el Análisis de Loci Microsatélites. Conservation Biology (1996), no. 10 (2), 376-389.

[21] R. Caniglia, E. Fabbri, C. Greco, M. Galaverni, L. Manghi, Boitani L, A. Sforzi, E. Randi, Black coats in an admixed wolfx dog pack is melanism an indicator of hybridization in wolves? . Eur J Wildl Res (2013), no. 59, 543-555.

[22] J. Mallet, Hybridization as an invasion of the genome. Trends Ecol Evol (2005), no. 20 (5), 229237.

[23] J. H. Bohling, L. P. Waits, Factors influencing red wolf-coyote hybridization in eastern North Carolina, USA. Biological Conservation (2015), no. 184 (0), 108-116.

[24] R. Kays, A. Curtis, J. J. Kirchman, Rapid adaptive evolution of northeastern coyotes via hybridization with wolves, Vol. 6, (2010).

[25] A. Verardi, V. Lucchini, E. Randi, Detecting introgressive hybridization between free-ranging domestic dogs and wild wolves (Canis lupus) by admixture linkage disequilibrium analysis. Molecular ecology (2006), no. 15 (10), 2845-2855.

[26] J. F. Benson, B. R. Patterson, Inter-specific territoriality in a Canis hybrid zone: spatial segregation between wolves, coyotes, and hybrids. Oecologia (2013), no. 173 (4), 1539-1550.

[27] aD. H. Thornton, D. L. Murray, Influence of hybridization on niche shifts in expanding coyote populations. Diversity and Distributions (2014), no. 20 (11), 1355-1364; bE. Crispo, J.-S. Moore, J. A. Lee-Yaw, S. M. Gray, B. C. Haller, Broken barriers: Human-induced changes to gene flow and introgression in animals. BioEssays (2011), no. 33 (7), 508-518. 
[28] N. C. Ellstrand, D. Biggs, A. Kaus, P. Lubinsky, L. A. McDade, K. Preston, L. M. Prince, H. M. Regan, V. Rorive, O. A. Ryder, K. A. Schierenbeck, Got Hybridization? A Multidisciplinary Approach for Informing Science Policy. BioScience (2010), no. 60 (5), 384-388.

[29] M. Arnold, Evolution through Genetic Exchange Oxford University Press, (2007).

[30] J. Monzón, R. Kays, D. E. Dykhuizen, Assessment of coyote-wolf-dog admixture using ancestryinformative diagnostic SNPs. Molecular ecology (2014), no. 23 (1), 182-197.

[31] F. Boggiano, C. Ciofi, L. Boitani, A. Formia, L. Grottoli, C. Natali, P. Ciucci, Detection of an East European wolf haplotype puzzles mitochondrial DNA monomorphism of the Italian wolf population. Mammalian Biology - Zeitschrift für Säugetierkunde (2013), no. 78 (5), 374-378.

[32] E. von Essen, Whose Discourse is it Anyway? Understanding Resistance through the Rise of 'Barstool Biology' in Nature Conservation. Environmental Communication (2015).

[33] B. Fitzpatrick, M. Ryan, J. Johnson, J. Ciorush, E. Carter, Hybridization and the species problem in conservation. Current Zoology (2015), no. 61 (1), 206-216.

[34] aR. Lorenzini, R. Fanelli, G. Grifoni, F. Scholl, R. Fico, Wolf-dog crossbreeding: "Smelling" a hybrid may not be easy. Mammalian Biology - Zeitschrift für Säugetierkunde (2014), no. 79 (2), 149-156; bž. Andersone, V. Lucchini, J. Ozolinšs, Hybridisation between wolves and dogs in Latvia as documented using mitochondrial and microsatellite DNA markers. Mammalian Biology Zeitschrift für Säugetierkunde (2002), no. 67 (2), 79-90.

[35] B. L. Borg, S. M. Brainerd, T. J. Meier, L. R. Prugh, Impacts of breeder loss on social structure, reproduction and population growth in a social canid. Journal of Animal Ecology (2015), no. 84 (1), 177-187.

[36] A. V. Stronen, N. Tessier, H. Jolicoeur, P. C. Paquet, M. Hénault, M. Villemure, B. R. Patterson, T. Sallows, G. Goulet, F.-J. Lapointe, Canid hybridization: contemporary evolution in humanmodified landscapes. Ecology and Evolution (2012), no. 2 (9), 2128-2140.

[37] S. Haig, F. W. Allendorf, University of Nebraska, Lincoln, Nebraska, (2006).

[38] F. W. Allendorf, R. F. Leary, N. P. Hitt, K. L. Knudsen, L. L. Lundquist, P. Spruell, Intercrosses and the U.S. Endangered Species Act: Should Hybridized Populations be Included as Westslope Cutthroat Trout? Conservation Biology (2004), no. 18 (5), 1203-1213.

[39] E. Gese, F. Knowlton, J. Adams, K. Beck, T. Fuller, Managing hybridization of a recovering endangered species: The red wolf Canis rufus as a case study. Current Zoology (2015), no. 61 (1), 191-205.

[40] J. Linnell, V. Salvatori, L. Boitani, Vol. contract 070501/2005/424162/MAR/B2, (2008).

[41] V. Lukasik, S. Alexander, Human-Coyote Interactions in Calgary, Alberta. Human Dimensions of Wildlife (2011), no. 16 (2), 114-127.

[42] J. Lindberg, S. Bjornerfeldt, P. Saetre, K. Svartberg, B. Seehuus, M. Bakken, C. Vila, E. Jazin, Selection for tameness has changed brain gene expression in silver foxes. Current biology : $C B$ (2005), no. 15 (22), R915-916.

[43] E. K. Latch, L. A. Harveson, J. S. King, M. D. Hobson, O. E. Rhodes, Assessing Hybridization in Wildlife Populations Using Molecular Markers: A Case Study in Wild Turkeys. The Journal of Wildlife Management (2006), no. 70 (2), 485-492.

[44] aF. W. Allendorf, R. F. Leary, P. Spruell, J. K. Wenburg, The problems with hybrids: setting conservation guidelines. Trends in Ecology \& Evolution (2001), no. 16 (11), 613-622; bP. Wirtz, Mother species-father species: unidirectional hybridization in animals with female choice. Animal behaviour (1999), no. 58 (1), 1-12.

[45] P. Fisher, B. Warburton, D. Morgan, P. Cowan, J. Duckworth, in ANZCCART Conference, Auckland, New Zealand, (2008), pp. 89-94. 
[46] aR. Timm, R. Baker, R. Bennett, C. Coolahan, in Proceedings of the Twenty-First Vertebrate Pest Conference, Visalia, California, (2004), pp. 47-57; bM. Grinder, P. Krausman, in Proceedings of the Vertebrate Pest Conference, (1998), pp. 293-298.

[47] L. Naughton-Treves, S. Sanderson, Property, politics and wildlife conservation. World Development (1995), no. 23 (8), 1265-1275

[48] S. Rubin, C. Fish, Biodiversity prospecting: using innovative contractual provisions to foster ethnobotanical knowledge, technology, and conservation. Colorado Journal of International Environmental Law and Policy (1994), no. 5 (1), 23-58.

[49] J. Lorimer, C. Driessen, Wild experiments at the Oostvaardersplassen: rethinking environmentalism in the Anthropocene. Transactions of the Institute of British Geographers (2014), no. 39 (2), 169-181.

[50] K. Henderson, University of Victoria (2009).

[51] aA. Sjölander-Lindqvist, in Survival and Sustainability (Eds.: H. Gökçekus, U. Türker, J. W. LaMoreaux), Springer Berlin Heidelberg, (2011), pp. 15-27; bO. Krange, K. Skogen, When the lads go hunting: The 'Hammertown mechanism' and the conflict over wolves in Norway. Ethnography (2011), no. 12 (4), 466-489.

[52] E. von Essen, H. P. Hansen, H. Nordström Källström, M. N. Peterson, T. R. Peterson, The radicalisation of rural resistance: How hunting counterpublics in the Nordic countries contribute to illegal hunting. Journal of Rural Studies (2014).

[53] E. von Essen, M. P. Allen, Reconsidering Illegal Hunting as a Crime of Dissent: Implication for Justice and Deliberative Uptake Criminal Law \& Philosophy (2015), 1-16.

[54] C. Perrings, The ecology and economics of biological diversity: elements of a research agenda, Beijer International Institute of Ecological Economics, Royal Swedish Academy of Sciences, Stockholm, Sweden, (1992).

[55] R. E. Worcester, R. Boelens, in Wildlife Damage Management Conference, Lincoln, (2007).

[56] C. A. Palmer, What (If Anything) Do We Owe Wild Animals? Between the Species (2012), no. 16 (1), 4. 